\title{
Clinical electrophysiological effects of propranolol on normal sinus node function
}

\author{
MIGUEL VASQUEZ, REUBEN CHUQUIMIA, NARASIMHAN SHANTHA, \\ MUSHTAQ KHAN, AND ONKAR S. NARULA
}

\begin{abstract}
From the Division of Cardiology, Department of Internal Medicine, Cook County Hospital, Veterans Administration Hospital North Chicago, and The Chicago Medical School, Chicago, Illinois, USA.
\end{abstract}

SUMMARY In 35 patients aged 18 to 69 years (mean 48) with clinical, electrocardiographic, or electrophysiological evidence of normal sinus node function, the effect of intravenous propranolol $(0.1 \mathrm{mg} / \mathrm{kg})$ was assessed on 3 indices of sinus node function. The drug significantly prolonged sinus node cycle length $(12 \%)$, slightly prolonged the corrected sinus node recovery time $(15 \%)$, and slightly but insignificantly lengthened sinuatrial conduction time. Propranolol may be administered safely in patients with normal sinus node function without the fear of producing severe sinus bradycardia, sinuatrial block, sinuatrial pauses, or prolonged sinus asystole, after spontaneous or stimulation-induced conversion of a tachycardia.

For over a decade, propranolol has been used extensively in the management of patients with arrhythmias (Rowlands et al., 1965; Bath, 1966). Several studies have reported the electrophysiological effects of propranolol in isolated tissue preparations (Davis and Temte, 1968; Pollen et al., 1969), in the intact animal (Priola, 1973), and in man (Seides et al., 1974). Despite a large number of publications, there is little information on the electrophysiological effects of propranolol on the sinus node function in man (Grendahl et al., 1975; Strauss et al., 1976b). Previous studies (Seides et al., 1974) in general analysed the effect of propranolol on only one index of sinus node function, that is the changes in sinus node cycle length or rate. Except for a preliminary report (Chuquimia et al., 1977) from this laboratory, few data are available on the effects of propranolol in patients with normal sinus node function, in particular on the response of the sinus node to overdrive suppression and on sinuatrial conduction time. Recently Strauss et al. (1976b) have reported their results on the effect of propranolol in 10 patients with sinus node dysfunction. It is difficult to view their results with a proper perspective without the knowledge of its effects on normal sinus node function.

In view of its extensive clinical use in patients with various types of arrhythmias, especially atrial

Received for publication 18 August 1978 fibrillation, atrial flutter, or supraventricular tachycardia, which inherently produce overdrive suppression of the sinus node, the necessity to learn the effects of propranolol on various indices of normal sinus node function was realised. The purpose of this study was to analyse the effect of intravenous propranolol on sinus node function in patients with clinical and electrophysiological evidence of normal sinus node function.

\section{Subjects and methods}

Electrophysiological studies were performed in 35 patients. Patients ranged in age from 18 to 69 years (mean 48), with 16 men and 19 women. A complete history and physical examination were recorded. In each patient routine laboratory data, a standard 12 lead electrocardiogram, and a chest $x$-ray film were obtained. The patients included in this study consistently showed resting normal heart rates ( $>$ $60 / \mathrm{min}$ ) on serial electrocardiograms and showed no electrocardiographic (standard electrocardiogram and Holter recordings) or clinical evidence of sinus node dysfunction. In addition, none of the 35 patients had any evidence of sinus node dysfunction during electrophysiological studies which were performed for symptoms of syncope, dizziness, and/ or palpitations. The standard electrocardiogram was normal in 11 patients and showed a pattern of bundle-branch block in 9 patients. The remaining 
15 patients showed various arrhythmias, that is paroxysmal re-entrant supraventricular tachycardia (7), ventricular arrhythmia (7), and $2^{\circ}$ type 1 atrioventricular nodal block (1). In the cases with paroxysmal supraventricular tachcardia, the site of re-entry was either in the atrioventricular node or resulted from bypass tracts. None of the 35 patients showed any evidence of atrial fibrillation or atrial flutter. In 24 patients there was no clinical evidence of associated heart disease, besides the arrhythmia or the bundle-branch block pattern. One patient had arteriosclerotic heart disease and 10 had associated systemic hypertension. At the time of study all cardioactive drugs had been discontinued for an interval exceeding 3 drug half lives. In all patients informed consent was obtained. The patients were studied in the postabsorptive state after premedication with $100 \mathrm{mg}$ pentobarbitone sodium administered intramuscularly half an hour before the study.

Under fluoroscopic control and intracardiac electrographic monitoring, a bipolar electrode catheter, 5 French in size with ring electrodes 10 $\mathrm{mm}$ apart was introduced precutaneously from a femoral vein and placed in the His bundle region. His bundle electrograms were recorded as described previously (Narula et al., 1970). A second quadripolar pacing catheter with electrodes $10 \mathrm{~mm}$ apart was introduced into the right atrium via an antecubital vein, and positioned so that the proximal electrode pair was located in the region of the sinus node for recording high right atrial electrograms and the distal pair was used for atrial stimulation.

All recordings were made on a multichannel oscilloscopic photographic recorder at paper speeds of $100 \mathrm{~mm} / \mathrm{s}$ for analyses of $\mathrm{AH}$ and $\mathrm{HV}$ intervals, and paper speeds of 50 to $100 \mathrm{~mm} / \mathrm{s}$ were used during studies of sinus node function. Multiple electrocardiographic leads representing the 3 planes of the electrocardiogram were recorded simultaneously with the intracardiac recordings. Atrial stimulation studies were performed at double the diastolic threshold with stimuli $2 \mathrm{~ms}$ in duration. Atrioventricular conduction was analysed during sinus rhythm and atrial pacing.

After catheter placement, control observations of spontaneous sinus rhythm were made for a period of 10 minutes. During the last minute of the control period, 10 consecutive sinus cycles were measured to calculate the mean sinus cycle length (mean $\left.A_{1} A_{1}\right)$. Single premature atrial beats were induced during sinus rhythm after every 8 th sinus cycle for evaluation of sinuatrial conduction time. The entire sinus cycle was scanned by the placement of premature atrial beats of increasing prematurity in steps of 10 to $20 \mathrm{~ms}$ until the atrial refractory period was reached. After the sequence of premature atrial beats, spontaneous sinus rhythm was observed for another period of 2 minutes before analysis of sinus node recovery time. The sinus node recovery time was measured as previously described (Narula et al., 1972) by atrial pacing at 2 different cycle lengths (500 and $430 \mathrm{~ms}$ ) for a period of 2 minutes at each level. Atrial pacing at cycle lengths shorter than $430 \mathrm{~ms}$ was not used, as previous studies Mandel et al., 1971) have reported a decrease in sinus node recovery time with shorter pacing cycle lengths. Immediately after atrial pacing was stopped, 10 spontaneous sinus cycles were recorded and analysed. A rest period of 2 minutes was provided between each atrial pacing rate to permit sinus rhythm to return to control levels. In our study, the sinus cycles usually returned to control levels in less than 1 minute.

After control determinations were completed, propranolol was administered intravenously in a dosage of $0.1 \mathrm{mg} / \mathrm{kg}$ bodyweight at a rate of 1 $\mathrm{mg} / \mathrm{min}$. Total dose ranged from 5 to $10 \mathrm{mg}$. This dosage regimen has been reported (Seides et al., 1974) to produce average plasma levels of 13.6 $\mathrm{ng} / \mathrm{ml}$ for 45 to $60 \mathrm{~min}$ after administration of propranolol. Ten minutes after the infusion of the last drop of propranolol, 30 sinus cycles were recorded to obtain the post-propranolol mean sinus cycle length. Thereafter, studies were repeated as in control to measure sinuatrial conduction time and sinus node recovery time. These studies were usually completed in $\leqq 30$ minutes after the last dose of propranolol was given.

The blood pressure was carefully monitored throughout: the drop in systolic pressure was $\leqq 10$ $\mathrm{mmHg}$ in all cases. No complications requiring treatment occurred in any patient either during or after the study. The atrial stimulation studies (regular atrial pacing or premature atrial beats) did not produce any bouts of atrial fibrillation or flutter throughout the study. In none of the cases with a history of supraventricular tachycardia was the measurement of sinus node recovery time or sinuatrial conduction time affected by atrial stimulation studies. Regular atrial pacing at cycle lengths used for sinus node recovery time did not initiate supraventricular tachycardia. During scanning of the sinus cycle by premature atrial beats, supraventricular tachycardia was initiated (3 out of 7) with very early premature atrial beats and not during the zone of sinus node reset used for estimating sinuatrial conduction time. In order to enhance relaxation, patients were studied in a quiet atmosphere and a relatively dark room using as little light as was necessary for the operation of the stimulator and the physiological recorder. 
In each patient the intervals between successive atrial depolarisations were measured from the bipolar high right atrial electrogram. During the sequence of premature atrial beats, the following intervals were measured: (1) $A_{1} A_{1}$ which is defined as the interval between the 2 consecutive sinus cycles; (2) $A_{1} A_{2}$ the interval between the atrial electrograms of sinus origin and the premature atrial beat; (3) $A_{2} A_{3}$ (return cycle) the interval between the premature atrial beat and the succeeding sinus beat. The estimated sinuatrial conduction time was calculated by the recently described method of Strauss et al. (1976a) based on a mean of $\mathrm{A}_{2} \mathrm{~A}_{3}$ intervals falling in the latter portion of zone II (reset zone). Sinuatrial conduction time $=A_{2} A_{3}-A_{1} A_{1}$. The value thus obtained represents the sum total of conduction time into and out of the sinus node.

Sinus node recovery time was measured from the last paced atrial electrogram to the first escape atrial electrogram of sinus origin or the longest post-pacing pause. The corrected sinus node recovery time was obtained by deducting from the sinus recovery time the mean of 10 consecutive spontaneous sinus cycles, recorded immediately preceding each atrial pacing cycle length. The statistical significance of the difference in values of spontaneous sinus node cycle length, corrected sinus node recovery time, and estimated sinuatrial conduction time determined under control and after propranolol were tested using the paired $t$ test.

\section{Results}

(1) SINUS CYCLE LENGTH

During control the sinus node cycle length ranged from 559 to $955 \mathrm{~ms}$ (mean and SD $766 \pm$

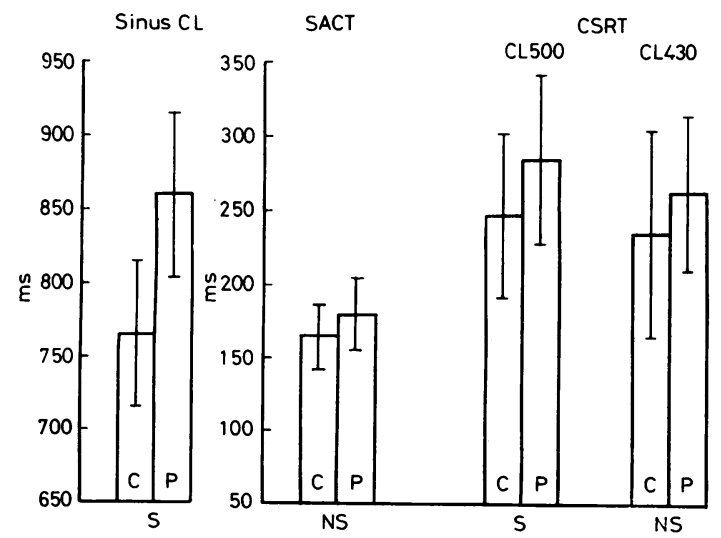

Fig The effects of propranolol on the 3 indices of sinus node function. NS, statistically not significant.
102) and after propranolol it ranged from 705 to $1090 \mathrm{~ms}$ (mean and SD $860 \pm 107$ ). After propranolol the sinus node cycle length increased by a range of 6 to $295 \mathrm{~ms}$ (mean 94) or by a mean of 12 per cent; this increase was statistically significant $(P<0.005)$ (Fig.) None of the patients manifested any electrocardiographic evidence of $2^{\circ}$ sinuatrial block or sinuatrial pauses after propranolol administration.

\section{(2) SINUATRIAL CONDUCTION TIME}

In 2 patients (cases 26 and 32), the sinuatrial conduction time during control was 175 and $118 \mathrm{~ms}$, and it could not be calculated after propranolol as the zone of sinus node reset could not be defined (Table). In the remaining 33 patients, the control sinuatrial conduction time ranged from 70 to $246 \mathrm{~ms}$ (mean $166 \pm 49$ ) and after propranolol it ranged from 100 to $285 \mathrm{~ms}$ (mean $182 \pm 49$ ). With propranolol, the sinuatrial conduction time was shortened (range 7 to $92 \mathrm{~ms}$ ) in 12 and lengthened (range 2 to $110 \mathrm{~ms}$ ) in 21 patients. The changes in sinuatrial conduction time after propranolol were not statistically significant.

\section{(3) CORRECTED SINUS NODE RECOVERY TIME}

On stopping atrial pacing, the first escape sinus node cycle was the longest in all except 4 of the 35 patients, in whom it was noted to be the second or the third sinus node cycle (Table).

The control corrected sinus node recovery time after atrial pacing at cycle length of $500 \mathrm{~ms}$ ranged from 83 to $520 \mathrm{~ms}$ (mean $247 \pm 113$ ) and after propranolol ranged from 90 to $605 \mathrm{~ms}$ (mean $284 \pm$ 115) (Fig.). After propranolol, the corrected sinus node recovery time at this atrial pacing rate was unchanged in 2, prolonged in 23 (range 15 to $415 \mathrm{~ms}$, mean $=97$ ), and shortened in 10 patients (range 20 to $175 \mathrm{~ms}$, mean $=93$ ). The control corrected sinus node recovery time after atrial pacing at a cycle length of $430 \mathrm{~ms}$ ranged from 10 to $525 \mathrm{~ms}$ (mean $235 \pm 137$ ) and after propranolol ranged from -55 to $494 \mathrm{~ms}$ (mean $=262 \pm 106$ ). After propranolol, the corrected sinus node recovery time at this atrial pacing rate was unchanged in 1, lengthened in 23 (range 25 to $276 \mathrm{~ms}$, mean $=102$ ), and shortened in 11 patients (range 5 to $345 \mathrm{~ms}$, mean $=125)$. After propranolol $17(49 \%)$ of the 35 patients showed a shortening in corrected sinus node recovery time at both atrial pacing cycle lengths. Before beta-blockade, in 8 of these 17 patients, the corrected sinus node recovery time had shortened during control as the atrial pacing rate was increased. 
Table Electrophysiological effect of propranolol on normal sinus node function

\begin{tabular}{|c|c|c|c|c|c|c|c|c|c|c|c|c|}
\hline \multirow[t]{3}{*}{ No. } & \multicolumn{2}{|c|}{ Age and sex } & \multirow{3}{*}{$\begin{array}{l}\text { Other electrocardiographic } \\
\text { features }\end{array}$} & \multirow{2}{*}{\multicolumn{2}{|c|}{ Sinus cycle length (ms) }} & \multirow{2}{*}{\multicolumn{2}{|c|}{$\begin{array}{l}\text { Sinuatrial conduction } \\
\text { time (ms) }\end{array}$}} & \multicolumn{5}{|c|}{ Corrected sinus node recovery time (ms) } \\
\hline & & & & & & & & \multicolumn{2}{|c|}{$A P C L=500$} & \multicolumn{3}{|c|}{$A P C L=430$} \\
\hline & & & & Pre & Post & Pre & Post & Pre & Post & Pre & Post & $t \overline{\bar{O}}$ \\
\hline 1 & 18 & $\mathrm{~F}$ & Normal PR, QRS, and axis & 710 & 830 & 150 & 100 & 90 & 90 & 185 & 150 & $\frac{\infty}{1}$ \\
\hline 2 & 18 & $M$ & $\begin{array}{l}\text { Lown Ganong Levine syndrome, } \\
\text { supraventricular tachycardia }\end{array}$ & 611 & 717 & 119 & 223 & 146 & 243 & 157 & 212 & $\stackrel{0}{\circ}$ \\
\hline 3 & 21 & $\mathbf{F}$ & $\begin{array}{l}\text { WPW and supraventricular } \\
\text { tachycardia }\end{array}$ & 559 & 757 & 78 & 123 & 237 & 357 & 235 & 337 & ڤొ \\
\hline 4 & 23 & $\mathbf{F}$ & $\begin{array}{l}\text { Premature ventricular } \\
\text { contractions }\end{array}$ & 870 & 990 & 175 & 200 & 125 & 245 & 85 & 305 & $\stackrel{\circ}{\overrightarrow{1}}$ \\
\hline 5 & 26 & $\mathbf{F}$ & Normal PR, QRS, and axis & 900 & 1005 & 160 & 235 & 520 & 605 & $290 \star$ & -55 & $\vec{\omega}$ \\
\hline 6 & 29 & $\mathbf{M}$ & Normal PR, QRS, and axis & 892 & 1020 & 131 & 114 & 265 & $158^{\star}$ & 10 & $112^{\star}$ & \% \\
\hline 7 & 30 & $\mathbf{F}$ & Normal PR, QRS, and axis & 682 & 740 & 188 & 190 & 273 & 340 & 234 & 343 & 己 \\
\hline 8 & 36 & $\mathbf{F}$ & Ventricular tachycardia & 950 & 968 & 165 & 172 & 367 & 293 & 525 & 347 & 7 \\
\hline 9 & 38 & $\mathbf{M}$ & Type $1,2^{\circ}$ atrioventricular block & 740 & 855 & 210 & 197 & 180 & 215 & 205 & 350 & 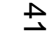 \\
\hline 10 & 40 & $\mathbf{M}$ & Supraventricular tachycardia & 915 & 940 & 245 & 215 & 145 & 260 & 180 & 320 & هे \\
\hline 11 & 42 & F & Left bundle-branch block & 775 & 850 & 205 & 285 & 215 & 380 & 295 & 350 & ?ריה \\
\hline 12 & 43 & $\mathbf{F}$ & $\begin{array}{l}\text { WPW and supraventricular } \\
\text { tachycardia }\end{array}$ & 700 & 720 & 170 & 120 & 175 & 195 & 130 & 105 & రి \\
\hline 13 & 45 & F & Supraventricular tachycardia & 629 & 718 & 113 & 147 & 95 & 510 & 120 & 310 & 으 \\
\hline 14 & 45 & $\mathbf{F}$ & Left bundle-branch block & 764 & 770 & 246 & 265 & 297 & 255 & 114 & 167 & \\
\hline 15 & 46 & $\mathbf{F}$ & Normal PR, QRS, and axis & 787 & 815 & 120 & 230 & 235 & 370 & 182 & 257 & 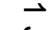 \\
\hline 16 & 50 & $\mathbf{M}$ & Normal PR, QRS, and axis & 680 & 705 & 170 & 245 & 110 & 180 & 60 & 160 & $\subsetneq$ \\
\hline 17 & 52 & $\mathbf{F}$ & Normal PR, QRS, and axis & 728 & 820 & 157 & 120 & 275 & 205 & 150 & 145 & 气 \\
\hline 18 & 52 & $\mathbf{M}$ & Supraventricular tachycardia & 700 & 850 & 180 & 220 & 380 & 250 & 500 & 210 & $\bar{D}$ \\
\hline 19 & 52 & $\mathbf{F}$ & Ventricular tachycardia & 830 & 880 & 210 & 170 & 280 & 205 & 125 & 290 & $\overrightarrow{0}$ \\
\hline 20 & 53 & $\mathbf{M}$ & $\begin{array}{l}\text { Right bundle-branch block and } \\
\text { left axis deviation }\end{array}$ & 875 & 955 & 190 & 205 & 430 & 515 & 290 & 360 & ขै \\
\hline 21 & 54 & $M$ & Left bundle-branch block & 700 & 760 & 85 & 170 & 152 & 247 & 125 & 170 & $\square$ \\
\hline 22 & 55 & $\mathbf{M}$ & Normal $P R, Q R S$, and axis & 898 & 926 & 158 & 130 & 245 & 310 & 400 & 380 & O \\
\hline 23 & 55 & $\mathbf{F}$ & $\begin{array}{l}\text { Prolonged QT, premature } \\
\text { ventricular contraction }\end{array}$ & 710 & 790 & 110 & 110 & 140 & 240 & 185 & 250 & $\sum$ \\
\hline 24 & 55 & $\mathbf{M}$ & Ventricular tachycardia & 680 & 790 & 240 & 250 & 400 & 440 & 460 & 410 & రి \\
\hline 25 & 57 & F & $\begin{array}{l}\text { Right bundle-branch block and } \\
\text { left axis deviation }\end{array}$ & 700 & 750 & 70 & 140 & 300 & 300 & 275 & 360 & $\stackrel{\varpi}{\mathbb{D}}$ \\
\hline 26 & 57 & $\mathbf{F}$ & Ventricular tachycardia & 760 & 960 & 175 & ND & 290 & 380 & 520 & 250 & \\
\hline 27 & 58 & $\mathbf{F}$ & $\begin{array}{l}\text { Right bundle-branch block and } \\
\text { left axis deviation }\end{array}$ & 725 & 795 & 230 & 235 & 231 & 324 & 216 & 245 & $\overrightarrow{\overline{0}}$ \\
\hline 28 & 60 & $M$ & Normal PR, QRS, and axis & 710 & 737 & 180 & 173 & 410 & 325 & 260 & 305 & $\frac{2}{2}$ \\
\hline 29 & 60 & $M$ & $\begin{array}{l}\text { Right bundle-branch block and } \\
\text { left axis deviation }\end{array}$ & 730 & 855 & 100 & 190 & 83 & 105 & 25 & 50 & 劳 \\
\hline 30 & 64 & $\mathbf{M}$ & $\begin{array}{l}\text { Right bundle-branch block and } \\
\text { left axis deviation }\end{array}$ & 860 & 980 & 165 & 180 & 165 & 145 & 200 & 180 & 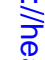 \\
\hline 31 & 65 & $\mathbf{F}$ & Left bundle-branch block & 955 & 1000 & 155 & 125 & 128 & 264 & 218 & 494 & ڤ్ర \\
\hline 32 & 65 & $\mathbf{M}$ & $\begin{array}{l}\text { Premature ventricular and atrial } \\
\text { contractions }\end{array}$ & 927 & 1090 & 118 & ND & $305^{\star}$ & 130 & 320 & 410 & $\frac{\vec{q}}{\bar{\sigma}}$ \\
\hline 33 & & $\mathbf{M}$ & Normal $P R, Q R S$, and axis & 730 & 840 & 210 & 195 & 285 & 320 & 470 & 235 & $\underline{3}$ \\
\hline 34 & 69 & $\mathbf{M}$ & Normal PR, QRS, and axis & 705 & 910 & 242 & 150 & 460 & 310 & 320 & 320 & ถ் \\
\hline 35 & 69 & $\mathbf{F}$ & Supraventricular tachycardia & 715 & 1010 & 135 & 200 & $215^{\star}$ & 230 & 140 & 240 & \\
\hline & & & Mean \pm SD & 766 & $860 \pm 107$ & $164 \pm 49$ & $182 \pm 49$ & 247 & $3284 \pm 115$ & 235 & $7262 \pm$ & \pm 0 \\
\hline
\end{tabular}

*Longest escape sinus cycle was 2nd or 3rd cycle.

AP, atrial pacing; CL, cycle length; ND, not definable.

With propranolol, the increase $(15 \%)$ in mean corrected sinus node recovery time (from 247 to 284) after atrial pacing at a cycle length of $500 \mathrm{~ms}$ was statistically significant $(P<0.025)$. However, the increase in corrected sinus node recovery time (from 235 to $272 \mathrm{~ms}$ ) after atrial pacing at a cycle length of $430 \mathrm{~ms}$ was not statistically significant. In addition, when the data of maximum or the longest corrected sinus node recovery time at either of the atrial pacing cycle lengths are reviewed, the maximum time: (a) increased from a mean of $284 \pm 130$ to $317 \pm 112 \mathrm{~ms}$ and (b) lengthened in 25 and shortened in 10 patients after propranolol. In this study of patients with normal sinus node function, there was no difference in response to propranolol related to the presence or absence of associated arrhythmias.

\section{Discussion}

In the past 6 years, atrial pacing studies have been extensively used for electrophysiological evaluation of sinus node function in man, both for investigative and clinical purposes. With the increasing use of such techniques, it has become apparent that at times in patients with previously documented sinus node 
dysfunction, the evaluation of sinus node function by electrophysiological means is within normal limits at the time of the study. These observations raise questions as to whether the electrophysiological testing procedures are inadequate and unreliable or whether the laboratory results return to normal because of an increase in release of stored catecholamines resulting from the stress of cardiac catheterisation. If the latter possibility is true, then it may be argued that patients requiring evaluation of sinus node function for clinical purposes may be analysed with greater accuracy by blocking the effect of increased catecholamines with propranolol administration.

Recently Strauss et al. (1976b) attempted to evaluate this consideration in 10 patients who were thought to have symptomatic sinus node dysfunction. However, only 2 of the 10 patients had abnormal corrected sinus node recovery time during control and both showed a severe prolongation of corrected sinus node recovery time after propranolol. In 5 other patients, the corrected sinus node recovery time changed by $\leqq 58 \mathrm{~ms}$ with propranolol. Since the effect of propranolol on normal sinus node function was not known, their observations cannot be reviewed from a proper perspective and have failed to satisfy the questions raised above. Their study left several questions unanswered. Does propranolol have a significant effect on sinus node recovery time in both patients with normal and abnormal sinus nodes? Is the severe prolongation of sinus node recovery time noted in 2 of the 10 cases an unusual response, or is it indicative of severe sinus node dysfunction?

Our data in patients with normal sinus node function show that with propranolol sinus cycles lengthened significantly $(P<0.005)$ with an average increase of 12 per cent. This prolongation in sinus cycle length is slightly less as compared with 16 per cent (Seides et al., 1974) and 22 per cent (Stern and Eisenberg, 1969) reported by others. The difference between our results and those of others may be explained by the fact that our patients were premedicated with pentobarbitone sodium whereas others obtained their data in nonsedated patients, possibly with higher levels of released catecholamines. The greater the betaadrenergic stimulus, the greater the response to beta-adrenergic blockade. In our patients, the control sinus cycle lengths noted at the time of the study were usually similar to those noted on routine electrocardiograms. This suggests that possibly there was no obvious increase in catecholamine release during the electrophysiological study.

After propranolol, though the mean corrected sinus node recovery time lengthened after each of the atrial pacing levels $(120 / \mathrm{min}$ and $140 / \mathrm{min})$, it was statistically significant only after atrial pacing at $120 / \mathrm{min}$. In addition, in 49 per cent of the patients the corrected sinus node recovery time, at either of the pacing cycle lengths, decreased after propranolol. Previous studies (Breithardt and Seipel, 1976) have indicated a faster conduction into the sinus node with sympathetic stimulation or with parasympathetic blockade after atropine. Therefore, the converse is also possible, that is an increased conduction delay or entrance block into the sinus node with sympathetic blockade. A decrease in corrected sinus node recovery time with propranolol may be explained on the basis of an enhanced entrance block into the sinus node and which, compared with the control levels, was manifested in some at lower atrial pacing rates. However, a lack of significant increase in sinuatrial conduction time with propranolol fails to support such a possibility.

If, in fact, propranolol enhances entrance block into the sinus node, it may possibly obscure the demonstration of sinus node dysfunction and may mask prolongation of the sinuatrial conduction time. Recently reported observations (Strauss et al., 1976b) of a distinct prolongation of corrected sinus node recovery time with propranolol in some and not all of the cases with clinically diagnosed sinus node dysfunction may suggest that: (a) if in patients with sinus node dysfunction, as discussed above, a protection from overdrive suppression does exist, it does not apply to all of the cases with sick sinus node; and (b) depending upon the response to propranolol, it may be possible to differentiate the various underlying mechanisms responsible for sick sinus syndrome, that is abnormalities of sinuatrial conduction and of the generator function of the sinus node.

During experiments in isolated tissues, it has been previously noted (Rosenbleuth, 1950) that in order to produce slower sinus rates or asystole it is necessary to affect all sinus node pacemaker fibres by acetylcholine, whereas only a few sinus node pacemaker fibres need be accelerated by norepinephrine to produce an increment in the heart rate. Therefore, it may be reasoned that in patients with sick sinus node, only a few sinus node pacemaker fibres may be functioning under the influence of available catecholamines which are sufficient to sustain sinus rhythm. In such patients, a withdrawal of catecholamine influences and beta-adrenergic blockade with propranolol may not only result in slower sinus node rates but also show a pronounced suppression to overdrive pacing or a distinct prolongation of the sinus node recovery time.

In our series, the maximum corrected sinus node 
recovery time at either of the atrial pacing rates showed a mean prolongation of $33 \mathrm{~ms}(11 \%)$ with propranolol. None of the patients showed a severe prolongation in corrected sinus node recovery time similar to that observed by Strauss et al. (1976b) in 2 of their 10 cases with sinus node dysfunction. On the basis of present data, it may be suggested that in the dosage used in this study and in therapeutic doses, propranolol may be safely administered when required to patients with electrophysiologically normal sinus node function without affecting it adversely. Accordingly, the evaluation of sinus node recovery time with and without propranolol may be clinically useful, before the institution of propranolol therapy, for detecting patients in whom a distinct adverse effect on sinus node function may occur, though extrapolation to patients on longterm oral treatment with propranolol may not be valid.

In all but 4 of the cases in our series, the first escape sinus node cycle after cessation of atrial pacing was the longest, both during control and after propranolol. This suggests that the secondary pauses are not common in cases with normal sinus node function and, when noted, may be suspicious of an overt or latent sinus node dysfunction. It may also be indirectly concluded that after propranolol administration a conversion of supraventricular tachycardia when associated with a long period of asystole probably indicates a sick sinus node. The asystole should not be interpreted merely as an expected side effect of propranolol. Such patients should be further investigated, in the absence of propranolol to confirm the diagnosis of sick sinus syndrome.

Previous workers (Breithardt and Seipel, 1976) have shown that sinuatrial conduction time is affected by autonomic influences, that is shortened by parasympathetic blockade or sympathetic stimulation. Our data show that though after propranolol there was a slight increase in the mean sinuatrial conduction time for the entire group, it was not statistically significant. It is difficult to evaluate properly the effect of propranolol on sinuatrial conduction time because of the limitations inherent in the present technique for its estimation (Strauss and Wallace, 1976).

The dosage of propranolol used in this study is similar to that used by others during electrophysiological studies in man (Seides et al., 1974; Strauss et al., 1976b). Propranolol in these doses produces 20 to 30 per cent blockade of exerciseinduced sinus tachycardia and requires a tenfold increase in the dose of isoprenaline to produce a given level of sinus tachycardia (Coltart and Shand, 1970). The plasma level resulting from this dosage regimen has been shown to have a significant betaadrenergic blocking effect. Mean serum levels of $13.6 \mathrm{ng} / \mathrm{ml}$ have been reported 45 to 60 minutes after propranolol administration with this dosage regimen (Seides et al., 1974). Our studies were generally completed within $30 \mathrm{~min}$ of the last dose of propranolol. In addition, this dosage regimen was selected to avoid unnecessary side effects or complications, that is hypotension which in turn may artificially alter the sympathetic and parasympathetic influences and thereby confuse the interpretation of the results. The results of the present study of an increase in sinus node cycle length, lengthening of corrected sinus node recovery time, and a possible prolongation of sinuatrial conduction time may all be explained on the basis of the betaadrenergic blocking effect of propranolol on the sinus node and the atrial myocardium.

\section{References}

Bath, J. C. J. L. (1966). Treatment of cardiac arrhythmias in unanesthetized patients. Role of adrenergic beta-receptor blockade. American fournal of Cardiology, 18, 415-425.

Breithardt, G., and Seipel, L. (1976). The influence of drugs on sinoatrial conduction time in man. In Diagnostic and Therapeutic Tools of Cardiac Pacing, pp. 58-72, ed B. Luderitz. Springer Verlag, New York.

Chuquimia, R., Vasquez, M., Qureshi, T., Khan, M., Towne, W. D., and Narula, O. S. (1977). Effect of propranolol on sinus node recovery time and sinoatrial conduction time (abstract). Clinical Research, 25, 212A.

Coltart, D. J., and Shand, D. G. (1970). Plasma propranolol levels in the quantitative assessment of $\beta$-adrenergic blockade in man. British Medical fournal, 3, 731-734.

Davis, L. D., and Temte, J. V. (1968). Effects of propranolol in the transmembrane potentials of ventricular muscle and Purkinje fibers of the dog. Circulation Research, 22, 661-677.

Grendahl, H., Miller, M., and Sivertssen, E. (1975). Registration of sinus node recovery time in patients with sinus rhythm and in patients with dysrhythmias. Acta Medica Scandinavica, 197, 403-408.

Mandel, W., Hayakawa, H., Danzig, R., and Marcus, H. S. (1971). Evaluation of sino-atrial node function in man by overdrive suppression. Circulation, 44, 59-66.

Narula, O. S., Cohen, L. S., Samet, P., Lister, J. W., Scherlag, B., and Hildner, F. J. (1970). Localisation of AV conduction defects in man by recordings of the His bundle electrogram. American fournal of Cardiology, 25, 228-237.

Narula, O. S., Samet, P., and Javier, R. P. (1972). Significance of the sinus node recovery time. Circulation, 45, 140-158.

Pollen, D. W., Scott, A. C., and Wallace, W. F. M. (1969). A comparison of the direct effects of $\mathrm{D} / \mathrm{L}$-and $\mathrm{D}$-propranolol in the electrical and mechanical behaviour of isolated frog ventricle. Cardiovascular Research, 3, 7-13.

Priola, D. V. (1973). Effects of beta-receptor stimulation and blockade on AV nodal and bundle-branch conduction in the canine heart. American fournal of Cardiology, 31, 35-40.

Rosenbleuth, A. (1950). Transmission of Nerve Impulses at Neuroeffector functions and Peripheral Synopses, p. 96. The Technology Press of Massachusetts Institute of Technology and John Wiley, New York.

Rowlands, D. J., Gowitt, G., and Markham, P. (1965) Propranolol (Inderal) in disturbances of cardiac rhythm. British Medical fournal, 1, 891-894. 
Seides, S. F., Josephson, M. E., Batsford, W. P., Weisfogel, G. M., Lau, S. H., and Damato, A. N. (1974). The electrophysiology of propranolol in man. American Heart fournal, 88, 733-741.

Stern, S., and Eisenberg, S. (1969). The effect of propranolol (Inderal) in the electrocardiogram of normal subjects. American Heart fournal, 77, 192-195.

Strauss, H. C., Bigger, J. T., jun, Saroff, A. L., and Giardina, E. G. V. (1976a). Electrophysiologic evaluation of sinus node function in patients with sinus node dysfunction. Circulation, 53, 763-776.

Strauss, H. C., Gilbert, M., Svenson, R. H., Miller, H. C., and Wallace, A. G. (1976b). Electrophysiologic effects of propranolol on sinus node function in patients with sinus node dysfunction. Circulation, 54, 452-459.

Strauss, H. C., and Wallace, A. G. (1976). Direct and indirect techniques in the evaluation of sinus node function. In The Conduction System of the Heart. Structure, Function and Clinical Implications, pp. 227-237, ed H. J. J. Wellens, K. I. Lie, and M. J. Janse. Stenfert Kroese, Leiden.

Requests for reprints to Professor Onkar S. Narula, Division of Cardiology, The Chicago Medical School, North Chicago, Illinois 60064, USA. 